\title{
UMA ANÁLISE DISCURSIVA DE EDITORIAIS CIENTÍFICOS: O caso da revista Varia Historia (2015-2016)
}

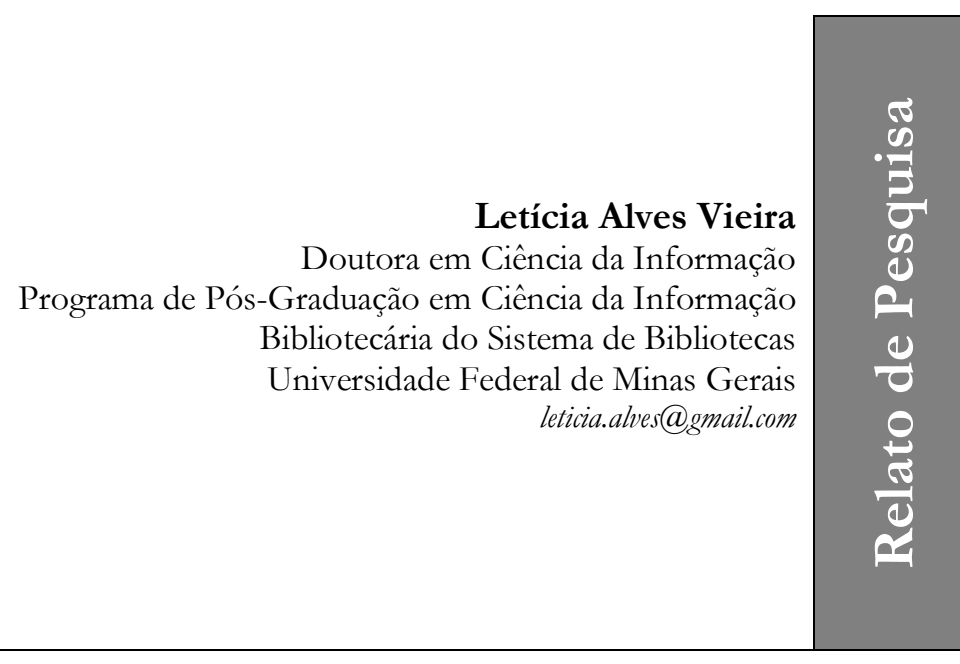

\section{Resumo}

Este artigo tem como objetivo analisar as estratégias discursivas e argumentativas veiculadas pelos discursos contidos nos editoriais publicados na revista Varia Historia. O recorte temporal compreende os anos de 2015 e 2016. Foram analisados seis editoriais, cujo corpus possibilitou extrair 14 trechos representativos para o estudo argumentativo. Para alcançar esse objetivo, foi realizada uma Análise do Discurso (AD), tendo como escopo a Teoria Semiolinguística (TS) de Patrick Charaudeau. Com base em uma situação triangular, que se constituiu de um sujeito argumentante, neste caso, representada pela editoria da revista Varia Historia, o sujeito alvo, que são os leitores da revista e a proposta sobre o mundo, o trabalho objetivou construir uma premissa para a atuação dos dois sujeitos. Em síntese, com a análise dos editoriais, foi possível compreender o potencial desse novo objeto como instância político-científica e o fazer científico em um domínio de conhecimento. O modelo de combinação teórico-metodológica, e um novo objeto - o editorial científico - mostrou-se profícuo para a compreensão dos elementos discursivos presentes nos editoriais, desvelando o conceito de ciência construído segundo as discussões acerca da neutralidade da própria ciência, a construção do saber acadêmico e suas relações com os saberes leigos, a política como assunto histórico, e, por fim, a preocupação com a internacionalização do periódico, e a circulação do conhecimento científico em História.

\section{Palavras-chave}

Análise do discurso. Comunicação científica. Editorial. Narrativa científica. Periódico científico.

\section{INTRODUÇÃO}

A comunicação científica como centro das atividades de pesquisa no cenário acadêmico é um tema recorrente de pesquisa na Ciência da Informação, conforme vários estudos presentes na literatura, desde a clássica obra de Meadows (1999), "A comunicação científica", até outras pesquisas com diferentes enfoques, sejam bibliométricos, altimétricos, teóricos, dentre outros. $\mathrm{E}$ a nossa escolha se baseia na comunicação científica como uma grande área de conhecimento, porém, com delimitações bastante definidas. Como uma ação científica, estudála se aplica a quaisquer campos de conhecimento.

Dessa forma, estabelecemos a demarcação para nosso estudo, a História, uma disciplina do campo das Ciências Humanas. E delimitamos um objeto em específico da comunicação científica, o periódico. E no interior do mesmo, escolhemos os editoriais como a emergência discursiva da ciência.

Para a realização dessa análise, utilizamos o recorte temporal que compreende os anos de 2015 e 2016, no qual o corpus se constitui com seis editoriais. O referencial 
teórico-metodológico adotado se baseia na Análise de Discurso, através da Teoria Semiolinguística de Patrick Charaudeau.

Além da introdução, o artigo encontra-se estruturado da seguinte forma: "Comunicação científica: um breve percurso", nesse tópico, o foco foi evidenciar o surgimento, semelhanças e diferenças entre os dois primeiros periódicos existentes e, portanto, precursores do periódico moderno como conhecemos hoje; "Referencial teórico-metodológico", onde apresentamos a combinação teórico-metodológica que orientou as análises empreendidas; "O editorial da revista científica como objeto e como gênero discursivo", que trata de um novo objeto e gênero discursivo na Análise do Discurso e, por isso, traz novidade para o estudo em comunicação científica na Ciência da Informação; "O conceito de ciência em História", que considera a polissemia presente no conceito de ciência e discute as particularidades deste no contexto dos editoriais objetos de análises; "Apresentação do corpus", análise dos dados e discussão dos resultados objetivo mostrar o corpus escolhido, a análise dos dados coletados e a discussão dos resultados, e ao final; e, por fim, "Considerações finais", que trazem as conclusões deste experimento e apontam a possibilidade de estudos futuros.

\section{COMUNICAÇÃO CIENTÍFICA: UM BREVE PERCURSO}

O início do periodismo científico esteve fundamentado na necessidade de agilidade da publicização dos conhecimentos gerados, bem como na amplitude dessa publicidade.

A comunicação epistolar apresentava limites em levar aos interessados o que de mais importante acontecia nos centros de ciência; pois, além das notícias científicas serem manuscritas, era necessário que se viajasse de um ponto onde o conhecimento tinha sido produzido para que o mesmo avançasse em outras cidades nas quais havia $\mathrm{o}$ interesse por ciência.

O periódico científico surge, assim, na segunda metade do século XVII por ra- zões que vão desde a expectativa de lucro por seus editores até a crença de que era necessário um debate coletivo das ideias tendo em vista novos descobrimentos. A motivação principal recai na necessidade de comunicação ágil e mais eficiente possível para a clientela interessada em novas realizações, conforme bem observou Meadows (1999). Para além dessas observações, de fato a introdução do periódico no ciclo de comunicação científica significou uma proposta de formalização desse processo. Os dois principais periódicos históricos - Journal des Savants e Philosophical Transactions - são fundamentais para estabelecermos uma linha temporal na configuração da ciência e na construção de narrativas científicas, no primeiro caso para as Humanidades - objeto de nosso interesse nessa pesquisa - e no segundo a narrativa científica clássica das áreas exatas e biológicas, áreas de cobertura do Philosophical.

Ambos surgem no século XVII, precisamente em 1665, sendo em janeiro daquele ano, o surgimento do Journal des Savants e meses mais tarde, o Philosophical Transactions. A trajetória deles é parecida, mas se diferem logo em seguida diante da proposta de cada um dos seus editores.

A proposta do Journal des Savants foi assim definida,

A intenção desse jornal é de informar o que acontece de novo na República das letras, ele será composto de um catálogo exato dos principais livros que serão impressos na Europa. E não nos contentaremos em dar simplesmente os títulos, como fizeram até agora maioria das Bibliografias: além disso, nós diremos de que eles tratam e em que eles podem ser úteis. Em seguida, na ocasião da morte de alguma pessoa célebre por sua doutrina ou por suas obras, nós a exaltaremos e faremos um catálogo do que ela terá criado, com as principais circunstâncias de sua vida. Em um terceiro momento, nós informaremos as experiências em Física e Química que possam servir para explicar os efeitos da natureza: as 
novas descobertas que acontecem nas Artes e nas Ciências, como as máquinas e as invenções úteis ou curiosas que podem fornecer as Matemáticas: observações do céu, dos meteoros e o que a anatomia poderá encontrar de novo nos animais. (VOLPE, 2008C), p. 28, tradução nossa $)^{1}$.

Enquanto o Journal des Savants trazia em seu primeiro fascículo um leque de atividades e cobertura, como catalogar e resumir os livros mais importantes da Europa, obituários entre outros já relatos anteriormente, o periódico londrino sugeria também ampla cobertura já denotada pelo seu título completo Philosophical Transactions: giving some Acompt of the presente Undertakings, Studies and Labours of the Ingenious in many considerable parts of the World, mas prevalecia o acordo já dito, não incluir temas polêmicos de natureza teológica e política, pois a sociedade científica se interessava apenas por estudos experimentais. A partir disso, podemos afirmar que o Philosophical Transactions foi o precursor do periódico moderno científico, e o Journal des Savants, após verificar que era impossível abarcar todas as pretensões descritas em seu primeiro fascículo, se concentrou em temas não científicos, podendo ser considerado o precursor do periódico moderno das Humanidades.

\footnotetext{
${ }^{1}$ Le dessein de ce Journal estant de faire sçavoir ce qui se passe de nouveau dans le République des lettres, il sera composé, primièrement d'um Catalogue exact des principaux livres qui s'imprimeront dans l'Europe. Et l'on ne se contentera pas de donner les simples titres, comme on fait jusques à présent la pluspart des Bibliographes: mais de plus on dirá de quoy ils traitens, et à quoy ils peuvent estre utiles. Secondement, quand il viendra à mourir quelque personne célèbre par sa doctrine et par ses ouvrages, on se fera l'Éloge, et on donnera um Catalogue de ce qu'il aura mis au jour, avec les principales circonstances de sa vie. En troisième lieu, on fera sçavoir les expériences de Physique et de Chymie, qui peuvent servir à expliquer les effets de la Nature: les nouvelles descouvertes qui se font dans les Arts et dans les Sciences, comme les machines et les inventions utiles ou curieuses que peuvent fournir les Mathématiques: les observations du Ciel, celles des Metéores, et ce que l'Anatomie pourra trouver de nouveau dans les animaux. (VOLPE, 2008C, p.28).
}

Conforme ressaltado, os primeiros periódicos constituíram-se por especificidades em relação à área de conhecimento a que pertencem, bem como à linha editorial escolhida de acordo com a influência da formação acadêmico-científica dos editores.

\section{REFERENCIAL TEÓRICO-METO- DOLÓGICO}

Do ponto de vista teóricometodológico, o presente artigo, tomou como base a Análise de Discurso, através da Teoria Semiolinguística de Patrick Charaudeau, corroborando com a abordagem da linguagem considerada pelo autor. Dessa forma, as atividades linguageiras podem ser categorizadas em modos de organização do discurso. Charaudeau (2009) os agrupou em quatro categoriais: o enunciativo, o descritivo, o narrativo e o argumentativo. Cada um tem na sua especificidade a ligação a uma finalidade discursiva dos sujeitos.

Nosso objetivo tanto na pesquisa como nesse artigo é a construção da narrativa científica através da análise discursiva dos editoriais, em função disto, nos ateremos no modo argumentativo.

Charaudeau (2009, p.201) afirma que "o argumentativo, [...] está em contato apenas com um saber que tenta levar em conta a experiência humana, através de certas operações do pensamento." O autor explica-nos que, enquanto o modo narrativo leva em conta as ações humanas e as confronta com uma forma de realidade que é visível e tangível, ele se difere do argumentativo.

Ainda segundo o autor, a argumentação não deve ser limitada a uma sequência de frases ou ainda de proposições ligadas por conectores lógicos. Para que haja a argumentação, é preciso existir uma proposta sobre algo e também uma provocação que gerará um questionamento, somando-se a um sujeito que vai se engajar em relação à proposição, outro sujeito que esteja relacionado com a proposta inicial e com o questionamento sobre a verdade, sendo assim o alvo da argumentação.

A construção do modo argumentativo se dá em uma relação triangular, confor- 
me a síntese representada na Figura 1 abaixo.

Em nosso estudo, o "Sujeito Argumentante" é representado pelo editor da revista Varia Historia, o "Sujeito Alvo" são os leitores da revista e a "Proposta" sobre o mundo é a construção de uma narrativa científica para a área de Humanidades a partir da História como disciplina representante.

Figura 1 - Relação triangular da argumentação

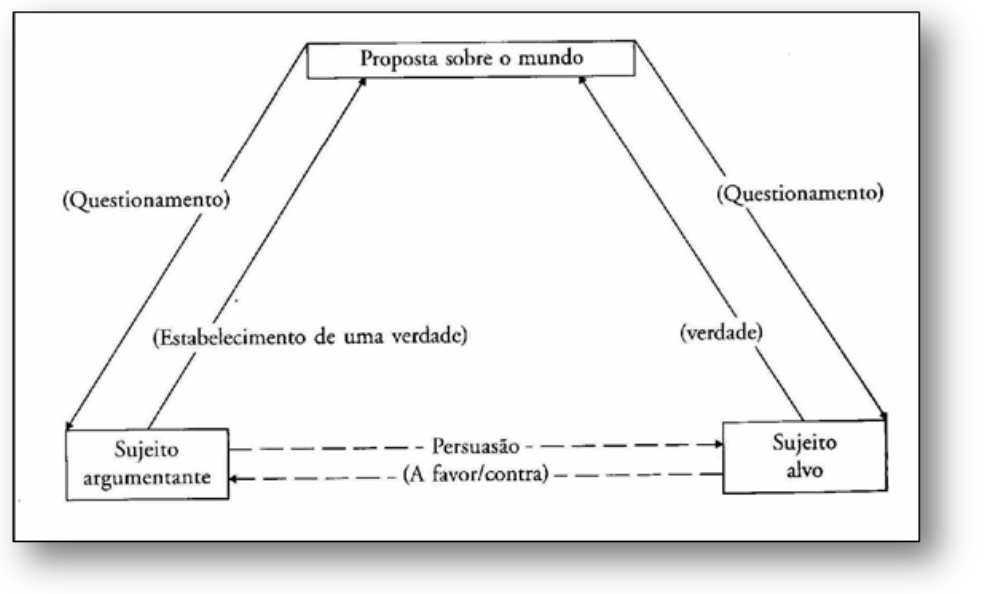

Fonte: Charaudeau (2009, p. 205).

Um processo argumentativo não deve ser somente um conjunto de asserções ou encadeamentos lógicos. O encandeamento de asserções constitui parte do processo argumentativo, denominado de proposta. Além dela, inicialmente, é necessário que o sujeito argumentante tome uma posição em relação à veracidade da proposta existente, ou seja, essa proposta deve estar relacionada ao que denominamos de proposição. A se- gunda envolve o fato de o sujeito dizer o motivo pelo qual está ou não de acordo, ou ainda, se o sujeito que propõe o questionamento é ele mesmo, deve trazer a prova de veracidade da sua proposta, desenvolvendo a persuasão. De forma resumida, temos o seguinte esquema.

Esse é o quadro teóricometodológico que orienta, neste estudo, a análise do corpus escolhido.

Figura 2 - Esquema do processo argumentativo

PROPOSTA

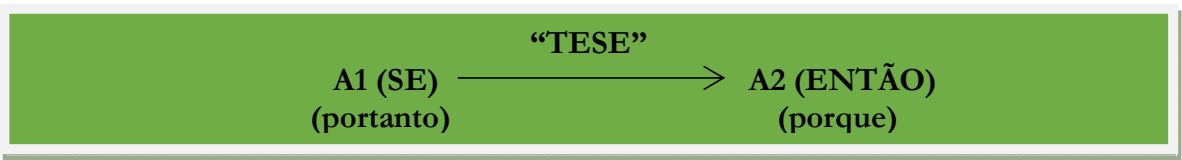

PROPOSIÇÃO

\section{"Quadro de posicionamento"}

Tomada de posição (refutação ou justificativa)

Não tomada de posição (ponderação)

\section{PERSUASÃO}

"Quadro de raciocínio persuasivo"

Prova de refutação, justificativa e ponderação

Fonte: adaptado de Charaudeau (2009, p. 225). 


\section{O EDITORIAL DA REVISTA CIEN- TÍFICA COMO OBJETO E COMO GÊNERO DISCURSIVO}

Geralmente o estudo de gêneros e também de narrativas na ciência estão ligados aos livros, textos acadêmicos, e claro, aos artigos científicos. O editorial como um gênero discursivo é passível de análise discursiva.

E o que é um editorial? Targino (1998) define que o editorial nas revistas científicas compõe as seções secundárias que representam o espaço para a manifestação e o posicionamento da publicação. Sua função primordial é a de representar a linha de pensamento da revista, além de apresentar o conteúdo do fascículo. De um modo geral, a redação dessas seções fica a cargo do editor do periódico, que constrói nesse contexto a sua narrativa, seu discurso.

Podemos inferir que a relevância e o diferencial no estudo de editoriais é que eles podem nos fornecer informações muito específicas quanto aos rumos políticos e científicos de uma área de conhecimento, se comparados aos artigos científicos. Nesse último, a opinião expressa é a do autor do trabalho, e o objetivo principal é a divulgação dos resultados de uma pesquisa ou mesmo a discussão de algum ponto teórico de determinada área de conhecimento. Os editoriais, por terem um papel diferente dentro do periódico, comportam um tipo de narrativa mais específica, que envolve a apresentação do fascículo, e também de reflexão sobre $\mathrm{o}$ campo de conhecimento no qual ele está inserido.

Nesse artigo, o foco recai sobre o editorial como um gênero discursivo $e$ objeto de análise. Em nossa pesquisa, o corpus foi composto de 23 editoriais da revista Varia Historia, compreendendo os anos de 2007 a 2016. Neste artigo, o recorte selecionado foi composto de seis editoriais dos anos de 2015 e 2016. A escolha desse recorte se deve às seguintes razões: distinção entre o texto de apresentação e editorial, que antes eram um texto único; padronização dos fascículos, um só editor nesse período, possibilitando assim verificar a linha editorial e o discurso empreendido nesse conjunto de editoriais. O modo como o conceito de ciência foi tratado na revista durante $\mathrm{o}$ período de 2015 a 2016, aponta elementos que podem contribuir nossa análise discursiva.

\section{O CONCEITO DE CIÊNCIA EM HISTÓRIA}

A ciência é polissêmica, contudo, nesse trabalho nos ateremos ao conceito extraído do Dicionário de Conceitos Históricos, trazendo de forma sucinta a concepção dos autores da área de História. Para Silva e Silva (2010, p.55), ciência
pode ser entendida tanto como processo de investigação para se chegar ao conhecimento quanto como o conjunto de conhecimentos construído com base na observação empírica do meio natural e social, que tem como finalidade fornecer fundamentos que permitam à humanidade viver mais e melhor no mundo que a cerca.

O Quadro 1 sistematiza o percurso do conceito no período coberto pela pesquisa.

A construção do conceito de ciência através das narrativas presentes nos editoriais passou pela reflexão acerca da técnica, da neutralidade da própria ciência e do fortalecimento de algumas temáticas de estudos que pareciam estar relegadas a segundo plano na área da História, como por exemplo, o estudo da direita política, das Américas e da América Latina, e também, da inteligência.

Tem-se também abertura a novas técnicas e novos olhares para objetos de pesquisa já conhecidos como a História e a escravidão. Porém, o que mais chama a atenção e aparece com mais frequência nos editoriais mais recentes é a preocupação com o periódico cientifico e a sua configuração. Nesse sentido, observa-se a preocupação com formatação de uma revista científica, 
sua função como instância de produção e circulação do conhecimento produzido em História. No contexto do editorial, o editor assinala a preocupação com a qualidade dos resumos, da escrita em História e da circulação desse conhecimento produzido, estabelecendo assim diretrizes importantes para a aceitação dos artigos submetidos ao periódico.

Quadro 1 - O conceito de ciência identificado nos editoriais de Varia Historia (2007-2016)

\begin{tabular}{|c|c|}
\hline Ano & O conceito de ciência na revista Varia Historia \\
\hline 2007 & $\begin{array}{l}\text { Neutralidade da ciência, uso da técnica, objetividade, fortalecimento da área de estudos da História das Amé- } \\
\text { ricas no Brasil, colaboração dos pesquisadores para o tema em questão. }\end{array}$ \\
\hline 2008 & $\begin{array}{l}\text { Estudo da diversidade sócio-histórica, reflexão e construção do diálogo entre várias disciplinas, relações entre } \\
\text { História e natureza, aspectos visíveis e invisíveis da arte e História. }\end{array}$ \\
\hline 2009 & $\begin{array}{l}\text { Construção do saber acadêmico e suas relações com os saberes leigos, articulação entre Medicina-Estado- } \\
\text { sociedade, profissionalização no campo da saúde, construção do saber científico. }\end{array}$ \\
\hline 2010 & $\begin{array}{l}\text { Novas perspectivas para o estudo da História Medieval (novas fontes), saúde e História, estabelecimento de } \\
\text { um vínculo entre conhecimentos científicos e ideologias políticas. }\end{array}$ \\
\hline 2011 & Estudos dos temas política, república, cultura e patrimônio através da História. \\
\hline 2012 & Inteligência e História como pesquisa acadêmica \\
\hline 2013 & $\begin{array}{l}\text { O periódico como instância de produção científica e discursiva, a reestruturação do periódico Varia Historia, } \\
\text { a História como ciência, colaboração internacional. }\end{array}$ \\
\hline 2014 & $\begin{array}{l}\text { A política como assunto histórico (o estudo da direita), os intelectuais e a História na América Latina como } \\
\text { campo de investigação. }\end{array}$ \\
\hline 2015 & $\begin{array}{l}\text { Resgate da trajetória do periódico, o papel da escrita na História, a História como ciência, construção das } \\
\text { narrativas históricas, o papel dos periódicos na consolidação e avanço científicos. }\end{array}$ \\
\hline 2016 & $\begin{array}{l}\text { Preocupação com a internacionalização do periódico, circulação do conhecimento científico em História e } \\
\text { melhoria na qualidade dos resumos/abstracts. }\end{array}$ \\
\hline
\end{tabular}

Fonte: elaborado pela autora (2017).

Essas ações impactam diretamente na condução de pesquisas da área e sua posterior divulgação, pois, através da padronização desses elementos, um pesquisador não teria estranhamento ao ver um periódico nacional e um periódico internacional. Dessa forma, o modus operandi científico tende a tornar-se normatizado e abrangente.

A utilização do espaço do editorial que geralmente é um acordo tácito entre editor e leitor foi um espaço de reflexão e discussão para além da formalidade de apresentação do fascículo publicado. Através dos argumentos utilizados de qualidade, internacionalização, ciência, dentre outros, a editoria ao longo dos anos conseguiu sensibilizar tanto os leitores quanto os autores e pareceristas da importância desse veículo de comunicação científica, colocando a revista Varia Historia como uma importante referência para a área no que tange à disseminação do conhecimento histórico produzido no Brasil, na Universidade Federal de Minas Gerais (UFMG) e no Departamento de História da Faculdade de Filosofia e Ciências Humanas (FAFICH).

\section{APRESENTAÇÃO DO CORPUS, ANÁLISE DOS DADOS E DISCUSSÃO DOS RESULTADOS}

No corpus original, o termo "Editorial" foi encontrado pela primeira vez no volume 4, número 7 do ano de 1988. A partir do ano de 2007, o texto intitulado "Editorial" começou a aparecer sistematicamente, e a partir do ano de 2015, precisamente no volume 31 , número 55 , há a presença de fato de dois textos distintos: um de apresentação do fascículo e do Editorial. O corpus para esse artigo é composto por seis editoriais que cobrem os anos de 2015 e 2016, conforme o Quadro 2. 
Quadro 2 - Editoriais de Varia Historia (2015 - 2016)

\begin{tabular}{|c|c|c|c|c|c|c|c|}
\hline & & & EDITO & IAIS VARIA HIS & PRA (20 & - 2016) & \\
\hline Editorial & Ano & Volume & Número & Dossiê & $\begin{array}{l}\text { Editor- } \\
\text { chefe }\end{array}$ & $\begin{array}{c}\text { Áreas de pesquisa do } \\
\text { editor-chefe }\end{array}$ & Período \\
\hline 01 & 2015 & 31 & 55 & $\begin{array}{l}\text { Por uma nova } \\
\text { Igreja Medieval }\end{array}$ & \multirow{6}{*}{$\begin{array}{l}\text { Regina } \\
\text { Horta } \\
\text { Duarte }\end{array}$} & \multirow{6}{*}{$\begin{array}{l}\text { História do Brasil Re- } \\
\text { pública, História e Na- } \\
\text { tureza, História da bio- } \\
\text { logia na Primeira Repú- } \\
\text { blica }\end{array}$} & \multirow{6}{*}{$\begin{array}{c}2015 \text { - } \\
\text { atualmente }\end{array}$} \\
\hline 02 & 2015 & 31 & 56 & $\begin{array}{c}\text { Historiografia e } \\
\text { História } \\
\text { Intelectual }\end{array}$ & & & \\
\hline 03 & 2015 & 31 & 57 & $\begin{array}{l}\text { Fascículo com } \\
\text { artigos avulsos }\end{array}$ & & & \\
\hline 04 & 2016 & 32 & 58 & $\begin{array}{l}\text { Culturas alimenta- } \\
\text { res, práticas e } \\
\text { artefatos }\end{array}$ & & & \\
\hline 05 & 2016 & 32 & 59 & $\begin{array}{l}\text { História e Teatro } \\
\text { no Brasil pós- } 64\end{array}$ & & & \\
\hline 06 & 2016 & 32 & 60 & $\begin{array}{l}\text { Arte e Ciência, } \\
\text { um processo } \\
\text { imperativo }\end{array}$ & & & \\
\hline
\end{tabular}

Fonte: elaborado pela autora (2017).

Durante esse período foram publicados cinco dossiês temáticos e um fascículo com artigos avulsos. A editora responsável é a professora Regina Horta Duarte, e suas áreas de pesquisa são: História do Brasil República, História e Natureza, História da Biologia na Primeira República. Em uma leitura desse quadro, podemos inferir que a área de pesquisa da editoria não influenciou as temáticas publicadas nesse período.

Para proceder à análise discursiva dos editoriais, primeiramente foi aplicado o quadro do dispositivo argumentativo considerando a relação triangular apresentada anteriormente pela Figura 1. Dessa forma, foi realizada a organização argumentativa do corpus. Com foco na proposta, apresentamos aqui as análises, nas quais verificamos as relações descritas anteriormente. Onde, de maneira geral, uma "Proposta" compõe-se de uma "asserção de partida (A1)", uma "asserção de chegada (A2)" e "uma asserção de passagem".

Trecho 01: "Em 1985, os estudantes do curso de graduação em História da UFMG receberam um desafio: todos podiam propor um título para a nova revista, e o vencedor ganharia uma coleção de livros de Eric Hobsbawm. Inventamos títulos mirabolantes, pretensiosos, com ex- pressões de efeito." (editorial 01, volume 31, número 55, 2015).

Proposta: (A1) SE os alunos do curso de graduação em História da UFMG aceitassem o desafio (A2) ENTÃO, haveria um concurso para escolha do nome da nova revista. PORTANTO, não era necessário nada mirabolante, pois mesmo assim o vencedor ganharia a coleção de livro de Eric Hobsbawm.

Trecho 02: "Quem plantou o sonho da revista foi Ciro Flávio Bandeira de Mello, colega de erudição invejável combinada com a simplicidade de sábio professor, adorado pelos alunos e absolutamente apaixonado pela História. Foi o primeiro editor chefe, enfrentando todas as dificuldades práticas para efetivar a publicação, ao mesmo tempo em que nos encantou com a ideia de que o departamento produzia conhecimento de qualidade e demandava a criação de um veículo impresso." (editorial 01 , volume 31, número 55 , 2015).

Proposta: (A1) SE o sonho da revista foi plantado pelo Ciro Flávio Bandeira de Mello, (A2) ENTÃO, ele foi o primeiro editor chefe. PORQUE encantou os alunos com a ideia de que o departamento produzia 
conhecimento de qualidade e demandava a criação de um veículo impresso.

Trecho 03: "Algumas conquistas foram decisivas para a expansão da revista, como o aceite no Portal SciELO, em 2007, e a continuada avaliação pela Capes com Qualis A1, o que colocou Varia Historia no patamar das revistas de excelência na área de História no Brasil." (editorial 01, volume 31, número 55, 2015).

Proposta: (A1) SE a revista foi aceita no Portal SciELO, (A2) ENTAO, é continuamente avaliada e tem o Qualis A1. PORTANTO, isso a colocou no patamar de revistas de excelência na área de História do Brasil.

Trecho 04: "A escrita da história possui, inegavelmente, uma série de particularidades em relação às práticas de outros campos do saber. Há muito os historiadores estudiosos das sociedades humanas no tempo - abdicaram da pretensão de lidar com verdades absolutas, atentos à complexidade presente na construção das narrativas históricas, elas próprias realizadas no devir de diálogos intensos com o passado e o futuro, mas também com desafios e inquietações do tempo presente." (editorial 02, volume 31, número 56, 2015).

Proposta: (A1) SE a escrita da História possui uma série de particularidades em relação às práticas de outros campos do saber, (A2) ENTÃO, é necessário que os estudiosos das sociedades humanas e historiadores abdiquem da pretensão de lidar com verdades absolutas. PORTANTO, é necessário estar atento às complexidades presentes nas narrativas históricas.

Trecho 05: "O julgamento por pares é a prática fundadora do dia a dia das revistas. Sem aquele, estas velejariam ao sabor das ondas das idiossincrasias, das preferências e antipatias pessoais. A publicação sem revisores desfavorece o saber inovativo, aquele que desafia as certezas estabelecidas e interesses arraigados de grupos bem alojados no conforto de gabinetes, alimentados com elogios negociados, ou mesmo aquele conhecimento produzido por pessoas que iniciam sua carreira, não ocupam posição de prestígio, mas já trazem uma contribuição brilhante." (editorial 02, volume 31, número 56, 2015).

Proposta: (A1) SE o julgamento dos pares é a prática fundadora do dia a dia das revistas, ENTÃO, a publicação sem revisores desfavorece o saber inovativo. PORQUE afasta o conhecimento produzido por pessoas que iniciam sua carreira e não ocupam posição de prestígio, mas que já conseguem trazer contribuições brilhantes.

Trecho 06: "Os revisores são essenciais, portanto, para a qualidade de um periódico. Por isso, devem também ser respeitados pelo editor: as revistas recebem material em excesso para avaliação, e cabe ao editor e aos conselheiros decidirem, por uma primeira leitura e debate, o que pode ser imediatamente devolvido, levando aos pareceristas apenas o material que realmente se apresentar como especialmente promissor. Afinal, o tempo do parecerista é precioso e não pode ser desperdiçado." (editorial 02, volume 31, número 56, 2015).

Proposta: (A1) SE os revisores são essenciais, (A2) ENTÃO, é necessário que ele seja respeitado também pelo editor. PORTANTO, será levado aos pareceristas apenas o material que é promissor, afinal o tempo do parecerista é precioso e não deve ser desperdiçado.

Trecho 07: "A quem serve a publicação? Ao produzir saber, um investigador precisa de meios de comunicação eficientes para sua difusão. Pouco valem análises excelentes e dados inovadores quando esquecidos no fundo das gavetas. Publicar, ser lido, estimular o pensamento, abrir-se ao diálogo com os pares, oferecer-se como pedra fundamental para outras pesquisas, mas também arriscar-se à crítica e à superação do que se fez. Direi o que é óbvio, mas tantas vezes esquecido: publicar é fazer do conhecimento produzido uma coisa pública." (editorial 03, volume 31, número 57, 2015). 
Proposta: (A1) SE a publicação serve aos interessados na difusão do conhecimento, (A2) ENTÃO, o investigador ao produzir precisa saber quais são os meios de comunicação eficientes para a difusão do conhecimento produzido por ele. PORQUE essa difusão vai estimular outros pensamentos e fortalecer o diálogo entre os pares.

Trecho 08: "O conselho editorial de Varia Historia tem trabalhado com afinco para oferecer artigos inéditos e sólidos, que possam nutrir pesquisas, inovações, pensamentos e ações. Em nossos processos editoriais, lançaremos sempre uma questão aos potenciais autores: afinal, o que vocês têm a oferecer de verdadeiramente novo e realmente instigante aos leitores de refinado paladar?" (editorial 03, volume 31 , número 57,2015$)$.

Proposta: (A1) SE o conselho editorial de Varia Historia trabalha com afinco para oferecer artigos inéditos e sólidos, (A2) ENTÃO, em seus processos editoriais haverá uma questão para os potenciais autores refletirem. PORQUE o conselho editorial gostaria de saber o que de verdadeiramente novo e instigante os autores têm a oferecer aos leitores de refinado paladar?

Trecho 09: "Ser internacional: as revistas acadêmicas brasileiras comungam essa ambição. Entretanto, esse desejo imediatamente impõe definições que guiem as estratégias para sua realização: afinal, o que é um periódico internacional?”' (editorial 04 , volume 32 , número 58, 2016).

Proposta: (A1) SE as revistas acadêmicas brasileiras têm a ambição de serem internacionais, (A2) ENTÃO, esse desejo imediatamente impõe as definições e estratégias para essa realização. PORTANTO, o que é afinal um periódico internacional? Quais são suas peculiaridades?

Trecho 10: "As principais exigências de internacionalização consistem em 20 a $25 \%$ de pareceristas e autores de filiação estrangeira, $15 \%$ a $25 \%$ de editores associados estrangeiros que participem ativamente da gestão dos manuscritos, 25 a $30 \%$ de artigos inéditos em inglês. Esses pontos têm aspectos positivos e negativos. A meu ver, a busca de pareceristas fora do país pode realmente catapultar o prestígio e a qualidade do periódico." (editorial 04, volume 32 , número 58, 2016).

Proposta: (A1) SE Varia Historia quer ser internacional, (A2) ENTÃO, é necessário o cumprimento das principais exigências de internacionalização, que consistem em 20 a $25 \%$ dos pareceristas e autores serem de filiação estrangeira, além de outras exigências. PORTANTO, esses pontos têm aspectos positivos e negativos na condução da linha editorial.

Trecho 11: "Os desafios são imensos para a área de História, e nossas revistas têm realmente um longo caminho a percorrer, assim como a SciELO precisa sensibilizarse com aspectos que nos diferenciam de outros campos do conhecimento. [...] Cabe aos conselhos editoriais pressionarem a SciELO para que considere algumas características da História, mas também é preciso ouvir e valorizar o que esse portal está nos oferecendo e como vem nos estimulando em prol do aprimoramento das revistas." (editorial 04, volume 32, número $58,2016)$.

Proposta: (A1) SE os desafios para a área de História são imensos, (A2) ENTÃO, nossas revistas têm um longo caminho a percorrer. PORTANTO, cabe aos conselhos editoriais da área pressionarem a SciELO para que ele considere as características específicas da História.

Trecho 12: "Ao lidar com uma revista e o meio intelectual ao qual ela se conecta, um editor depara com uma das mais básicas exigências de todos os bons indexadores científicos: a revista deve ter abstracts bem estruturados, claros, e que expressem o conteúdo essencial do artigo, explicitando sua real contribuição. [...] Nem sempre a área de história valorizou suficientemente a escrita dos resumos. Muitas vezes, restringem-se a duas ou três mal traçadas linhas. Outras vezes apresentam-se excessivamente longos e imprecisos, sem realmente definirem as questões indispensáveis num resumo." (editorial 05, volume 32, número 59, 2016). 
Proposta: (A1) SE a área de História nem sempre valorizou suficientemente a escrita dos resumos, (A2) ENTÃO, o editor tem que lidar com uma das básicas exigências de todos os melhores indexadores científicos, que é a revista ter abstracts bem estruturados e claros. PORQUE expressam o conteúdo essencial do artigo, explicitando assim a sua real contribuição.

Trecho 13: "Desde o resumo, o autor se oferece ao julgamento entre os pares, à leitura crítica de seu artigo. Ele facilita, aos pesquisadores, uma consulta rápida e eficaz nas bases de pesquisa, possibilitando a pesquisa bibliográfica ampla, em diálogo com a produção acadêmica mundial." (editorial 05, volume 32, número 59, 2016).

Proposta: (A1) SE, a partir do resumo, o autor já oferece aos seus pares um julgamento, ou seja, a leitura crítica de seu artigo, (A2) ENTÃO, ele facilita aos pesquisadores a consulta rápida e eficaz. PORTANTO, o resumo possibilita uma pesquisa bibliográfica ampla e em diálogo com a produção acadêmica mundial.

Trecho 14: "Um periódico da área de História precisa ser movido por essas pretensões, para que não se torne um simples 'publicador' de artigos. Os melhores periódicos são como caçadores investigando rastros dos textos mais originais, das pesquisas mais inovadoras, mais bem fundamentadas, mais relevantes, aquelas que instigam o pensamento, que ousam dizer o que ainda não tinha sido dito, brindando o leitor com uma nova forma de ver e analisar um objeto de estudo." (editorial 06, volume 32, número 60, 2016).

Proposta: (A1) SE os melhores periódicos são como os caçadores investigando rastros dos textos mais originais, (A2) ENTÃO, um periódico da área de História precisa ser movido por essas pretensões, PORQUE senão ele torna apenas um simples "publicador" de artigos.

Dessa forma, a partir da organização argumentativa do corpus em análise, os trechos de (1) a (14) nos apontam na direção da construção de uma narrativa científica para a área de humanidades, com foco no periódico como elemento basilar para essa discussão. Podemos inferir que decorre da preocupação da editoria desse período, bem como a necessidade da internacionalização do periódico, associado às variáveis como avaliação do curso de pós-graduação, e que derivam dessa movimentação outras ações, como a manutenção da qualidade do programa, dos projetos financiados pelas agências de pesquisa, bem como da produção do conhecimento histórico atual.

\section{CONSIDERAÇÕES FINAIS}

O cenário inicial da pesquisa foi os editoriais da revista Varia Historia entre os anos de 2007 a 2016, porém, o presente estudo que trouxe desse conjunto mais amplo, a análise dos anos de 2015 e 2016, nos permitiu trazer à tona uma parte dos resultados da pesquisa.

No geral, podemos observar que o editorial é um objeto de instância política que permite compreender o fazer científico em um domínio de conhecimento. Nesse espaço, a fala do editor não se resume à apresentação do fascículo e seus artigos publicados. Esta instância discursiva é utilizada com o objetivo de legitimação do campo da História como ciência, orientações a respeito da ética em publicações, coordenação das publicações a partir da área de pesquisa na qual o editor tinha experiência, desenhando assim uma linha editorial do período analisado.

Já para o campo da comunicação científica, a possibilidade de identificar formações discursivas em editoriais, analisando assim uma construção da narrativa científica para uma área de conhecimento, forneceu subsídios para pensar o periódico como um espaço não somente da veiculação dos discursos oriundos dos resultados de pesquisa, das resenhas dos livros recém-publicados, e de outros documentos, mas como um conjunto de narrativas delimitadoras de um domínio científico, tendo um caráter políticocientífico, que auxilia na construção de um 
conceito de ciência para aquele campo do saber.

A Análise de Discurso utilizada como referencial teórico-metodológico, através de uma abordagem a partir da Teoria Semiolinguística de Charaudeau, com foco nos modos de organização do discurso, e o novo objeto - o editorial científico - se mostrou profícua para a compreensão dos elementos discursivos presentes nos editoriais, desvelando o conceito de ciência construído a partir das discussões acerca da neutralidade da própria ciência, a construção do saber acadêmico e suas relações com os saberes leigos, a política como assunto histórico, chegando até à preocupação com a internacionalização do periódico, e a circulação do conhecimento científico em História.

\title{
A DISCURSIVE ANALYSIS OF SCIENTIFIC EDITORIALS: The case of the journal Varia Historia (2015-2016)
}

\begin{abstract}
This article intends to analyze the main discursive and argumentative strategies adopted by the discourses found in the editorials of the journal V aria Historia. The research focused on the years of 2015 and 2016. A total of six editorials were analyzed from which fourteen representative excerpts were extracted for argumentative analysis. For this purpose, Discourse Analysis (DA) was employed in the scope of Patrick Charaudeau's Semiolinguistics theory. On the basis of a triangular situation constituted by an argumentative subject (here represented by the publisher of Varia Historia), a target subject (the readers of the magazine), and a proposition about the world, this article aims at building a premise for the acting of both these subjects. In sum, the analysis of the editorials enabled the understanding of the object's potential as a political-scientific instance and a practice inside a field of knowledge. This theoretical and methodological combination and a new object - the scientific editorial - were profitable for the comprehension of discursive elements in the editorials. They unveil the establishment of the concept of science in accordance with discussions concerning scientific neutrality, the construction of academic knowledge and its relations to lay knowledge, politics as a historical subject and, at last, the dissemination of knowledge in History.
\end{abstract}

Keywords

Discourse Analysis. Scientific communication. Editorials. Scientific narrative. Scientific journal. Artigo recebido em 09/05/2018 e aceito para publicação em 19/08/2018

\section{REFERÊNCIAS}

\section{CHARAUDEAU, P. Linguagem e discur-} so: modos de organização. São Paulo: Contexto, 2009.

MEADOWS, A. J. A comunicação científica. Brasília: Briquet de Lemos Livros, 1999.

SILVA, K. V.; SILVA, M. H. Dicionário de conceitos históricos. 3.ed. São Paulo: Contexto, 2010.
TARGINO, M. G. L. Comunicação científica: o artigo de periódico nas atividades de ensino e pesquisa do docente universitário brasileiro na pós-graduação. 1998. 378 f. Tese (Doutorado em Ciência da Informação) - Universidade de Brasília, Faculdade de Estudos Sociais Aplicados, Departamento de Ciência da Informação e Documentação. Brasília, 1998.

VOLPE, T. Science et Théologie dans les débats savants de la seconde moitié du XVII Siècle: la Genèse dans les Philosophical Transactions et le Journal des Savants (1665-1710). Belgium: Brepols, 2008C. 